\title{
Museos pequeños, estrategias digitales a medida. El caso del Museu d'Història de Manacor, (Mallorca)
}

Small museums, customized digital strategies. The casa of the Museu d'Història de Manacor (Mallorca)

\section{María José Rivas Antequera ${ }^{\mathrm{a}}$ Magdalena $\mathbf{M}^{\mathrm{0}}$ Salas Burguera ${ }^{\mathrm{b}}$}

aprofesional libre. wini 59@hotmail.com, birectora del Museu d'Història de Manacor. museu@manacor.org

\begin{abstract}
Resumen
Con esta comunicación queremos compartir en el I Congreso internacional de museos y estrategias digitales el desarrollo del Museo d'Història de Manacor en el ámbito digital, explicar cuáles han sido las dificultades para llegar hasta aqui y los logros que nos han permitido la implantación de nuevas formas de comunicación a través de las herramientas digitales.
\end{abstract}

Nuestra institución cuenta con un presupuesto limitado, es por eso por lo que creemos interesante desglosar los recursos tanto materiales como de personal que hemos dedicado a desplegar la estrategia digital para demostrar que también los museos pequeños podemos crear entornos digitales a nuestra medida.

Uno de nuestros objetivos es que la creación de un entorno digital abra el museo a otros espacios, hasta ahora desconocidos, que nos permitan generar alianzas con la comunidad más próxima y con todas las personas que se interesen en nuestra institución a través de las ventanas que estamos abriendo en el universo digital.

Palabras clave: accesibilidad, digitalización, página web, comunidad, relaciones.

\section{Abstract}

With this communication we want to share in the I International Congress of Museums and Digital Strategies the development of the Museo d'Historia de Manacor in the digital field, explain what the difficulties have been to get here and the achievements that have allowed us to implement new forms of communication through digital tools. 
Museos pequeños, estrategias digitales a medida. El caso del Museu d'Història de Manacor, (Mallorca).

Our institution has a limited budget, that is why we believe it is interesting to break down the material and personnel resources that we have dedicated to deploying the digital strategy to show that small museums can also create digital environments to suit us.

One of our objectives is that the creation of a digital environment opens the museum to other spaces, until now unknown, that allow us to generate alliances with the closest community and with all the people who are interested in our institution through the windows that we are opening in the digital universe.

Keywords: accessibility, digitization, website, community, relationships. 


\section{Introducción}

El Museu d'Història de Manacor es un museo de ámbito local y territorial, de gestión municipal, situado en el municipio del Manacor, en el levante de la isla de Mallorca (con una población de más de 44.000 habitantes), que cuenta con una media de entre 9.000 y 10.000 visitantes anuales hasta el 2019.

Nuestra colección es mayoritariamente arqueológica pero también tenemos un fondo etnográfico y de patrimonio industrial importante. La colección es fruto de diferentes donaciones de particulares durante los últimos 95 años y de proyectos de investigación propios y excavaciones privadas de los últimos 30 años.

Como museo de tipo pequeño hemos desarrollado los últimos 5 años nuevas formas de comunicación a través del formato digital casi de manera autodidacta. Este proceso iniciado casi por inercia e interés propio ha llevado a explorar nuevas formas de comunicación no sólo digital sino también presencial que se han visto reforzadas con el confinamiento del $2020 \mathrm{y}$ todas las consecuencias que lleva consigo la pandemia que estamos sufriendo.

Nuestra institución que depende íntegramente de la financiación municipal cuenta con un presupuesto limitado y con sólo dos personas fijas en plantilla (la dirección y el informador del museo). Por este motivo, en este artículo vamos a desglosar los recursos tanto materiales como de personal que hemos dedicado a desarrollar la estrategia digital para demostrar que también los museos pequeños podemos crear estrategias digitales a nuestra medida.

Esta estrategia digital nos permite llegar a un público nunca antes imaginado y crear unos contenidos accesibles a diferentes tipos de públicos e inquietudes. De todos modos, de ninguna manera cambiaríamos la actividad presencial por la digital, pero sí que somos conscientes de las posibilidades de difusión que se abren y que no podemos dejar pasar. Cada institución, en su medida, puede desarrollar estrategias digitales. Claro que nos gustaría contar con una persona sólo dedicada a este tema, pero como por ahora, no es posible, consideramos que no hemos de cerrar una puerta sino simplemente abrirla y explorarla en la media de nuestras posibilidades.

\section{Objetivos}

Nuestro objetivo principal es entrar y formar parte del proceso de transformación digital actual para que el museo siga creciendo.

Los objetivos específicos son:

- Unirnos a través del diálogo digital con todo tipo de comunidades (territoriales, investigadoras, educadoras...).

- Facilitar la accesibilidad universal y la inclusión de cualquier persona al museo.

- Trabajar en todas las redes que nos facilite la tecnología. 
Museos pequeños, estrategias digitales a medida. El caso del Museu d'Història de Manacor, (Mallorca).

- Divulgar los contenidos del Museo.

- Mejorar y alentar la visita física a nuestros equipamientos con ayuda de las herramientas digitales.

\section{Desarrollo de la innovación}

Hasta 2017 nuestra incursión en el mundo digital se basaba en las siguientes acciones:

- El Museo contaba con una web propia pero que era administrada desde el Consell de Mallorca, es decir, no teníamos el control del diseño y de la inmediatez de los contenidos.

- Las salas de Antigüedad Tardía e Islámica contaban con actividades interactivas para el público que se realizaban con dos ordenadores.

- Redes sociales: el museo gestionaba de manera autónoma una cuenta de Instagram propia y de manera conjunta la cuenta de Facebook de los amigos del Museo de Historia de Manacor ya que no tenía cuenta propia.

La comunicación con nuestros visitantes asiduos se realizaba mediante correo ordinario y correo electrónico.

A partir de 2017 nuestra estrategia digital se basó en dos pilares:

\subsection{La renovación de la página web.}

Este proyecto fue el punto de partida sobre el que se sustentó el desarrollo del resto de plataformas y herramientas digitales.

La renovación de la web tenía como objetivos:

- Que se pudiese acceder a ella desde cualquier dispositivo informático (ordenador, tabletas, móviles).

- Que el personal del Museo la pudiese modificar en cualquier momento y que fuese accesible para nosotros ya que esto nos proporcionaba más autonomía y una presencia inmediata de la información en el entorno digital.

- Ser accesible para todos los usuarios.

- Independizarnos de la "web nodriza" a la que pertenecíamos.

El proyecto de renovación de la web coincidió con la formación que el equipo del Museo estaba llevando a cabo en accesibilidad. De esta manera, entendimos que era el momento ideal para implementar muchas de las acciones que algunos de nuestros compañeros estaban llevando a cabo en instituciones como el Vilamuseu (@vilamuseu) y Rede Museística Provincial de Lugo (@RedeMuseistica) y que la web nos ayudaría a aunar muchos de los cambios que queríamos hacer en el Museo. También nos formamos de manera autodidacta visitando páginas web de otras instituciones o blogs especializados en esta temática. 
La web sería nuestro puente entre el mundo físico y el digital, su renovación nos empujó a un cambio natural y adaptado a las necesidades del Museo. Fue de esta manera como empezamos a crear sin ser conscientes el propio entorno digital del museo, el cual está sustentado el $90 \%$ en la página web del museo y el $10 \%$ en las redes sociales.

La página web del museo está diseñada por la empresa Mopis $\mathrm{Web}^{1}$, pero sabíamos desde el principio, que crear una nueva página web era una labor conjunta entre el equipo del museo y una empresa especializada. Aprovechamos todo el trabajo de documentación (textos e imágenes) que se había hecho para la web anterior y a la vez se idearon contenidos e imágenes inéditos para la nueva web.

Cuáles son los cambios principales que se realizaron en la página web:

${ }_{1}$ www.mopisweb.com, empresa local con sede en el municipio de Manacor. 


\section{RENOVACIÓN WEB}
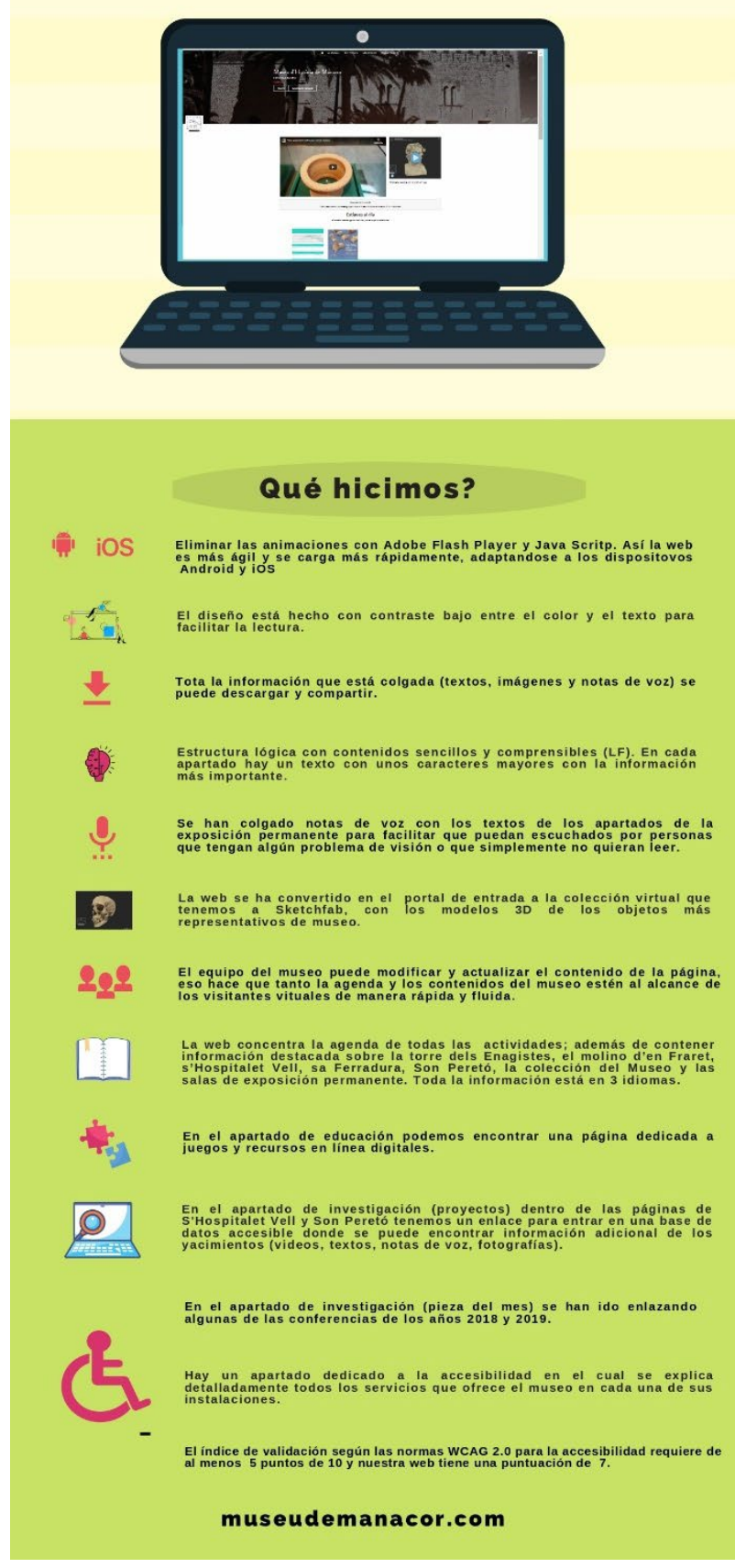

Diseño: María José Rivas

Fig. 1 Infografía con los cambios se realizaron en la web 
Una de las novedades de la página web es que tiene acceso directo a la colección virtual que tenemos en Sketchfab ${ }^{2}$. En esta plataforma de gestión de modelos 3D tenemos subidos 19 modelos con los objetos más representativos de nuestra colección permanente. De este modo, cualquier persona en cualquier parte del mundo puede visualizar, desde cualquier ángulo, estos objetos y escuchar la descripción de las piezas en diferentes idiomas. Es una vía para acercar el Museo a personas que de otro modo no tienen posibilidad de conocer la colección, ya sea por no poder venir físicamente a la institución o por tener algún tipo de discapacidad visual. También es importante el papel que desarrolla esta plataforma para el sistema educativo (desde universidades a colegios) ya que facilita el acceso a las piezas desde cualquier dispositivo móvil.

\subsection{Las redes sociales}

A partir del 2019 abrimos cuentas en Twitter, Facebook y YouTube para aprovechar estas plataformas para difundir nuestras actividades, aprender de otros centros, comunicar nuestros contenidos y poder tener relación directa con la comunidad más cercana y con cualquier usuario de las mismas. Del mismo modo, el realizar encuestas o concursos nos permitió potenciar la interactividad con cualquier persona interesada.

Instagram $^{3}$, Twitter ${ }^{4}$ y Facebook ${ }^{5}$ comparten publicaciones, la mayoría de las entradas ( 5 por semana) están creadas para dar a conocer la colección del museo, aunque también se usan como canales de difusión para las actividades diarias que se llevan a cabo, así como la agenda de actividades del museo. También se mantienen activas las herramientas de stories y fleets en las dos aplicaciones.

El uso de estas tres redes sociales se ha desarrollado en la medida que el personal del museo se ha ido formado en ellas. Al principio, las entradas eran más espontáneas y estos canales no ayudaban a dar difusión a nuestra actividad diaria. Aprendimos que para hacer un buen uso de ellas habría que planificar los contenidos que queríamos comunicar y adaptarlos al lenguaje digital, de esta forma se crearon publicaciones encadenadas sobre exposiciones temporales, material etnográfico, epigrafía, efemérides, ...etc. En este sentido, ha sido básico contar con la colaboración, conocimiento de diseño e imaginación de personal técnico joven que de manera temporal y puntual nos ayuda en esta tarea.

El canal de YouTube $^{6}$ sin embargo, es el espacio donde colgamos toda la producción audiovisual del museo, el $70 \%$ de estos videos están interpretados en lengua de signos y

\footnotetext{
${ }^{2}$ https://sketchfab.com/MuseuManacor?utm_medium=embed\&utm_source=website\&utm_campain=share-popup a fecha de hoy 16/02/2021 cuenta con más de 17.400 visitas.

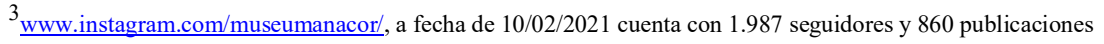

$4 @$ MuseuManacor, a fecha de 10/02/2021 cuenta con 268 seguidores.

${ }^{5}$ Museu d'Història de Manacor, a fecha de 10/02/2021 cuenta con 408 seguidores.

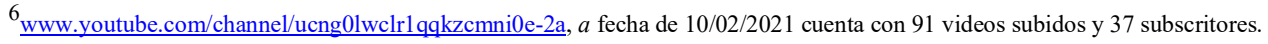


Museos pequeños, estrategias digitales a medida. El caso del Museu d'Història de Manacor, (Mallorca).

subtitulados en 2 idiomas (catalán, castellano e inglés). Algunos de estos videos (conferencias de la pieza del mes) son producciones "caseras" realizadas por el propio personal del museo, superando todas las críticas hacia la calidad de los videos hemos primado la intención de dejar documentadas conferencias que se han creado especialmente para el museo por profesionales de la investigación y que normalmente no se vuelven a repetir. En la plataforma de videos también se han colgado los talleres en línea, actividad que se inició durante el confinamiento de 2020 y que ha continuado durante este 2021.

A través de las redes sociales se lanzó durante el confinamiento del 2020 la actividad "El millor de cada casa" (Lo mejor de cada casa) que animaba a la gente a mostrar y compartir un objeto que tuviese en su casa y que tuviese un significado simbólico o histórico especial. A través del hashtag \#elmillordecadacasa se compartieron durante semanas estos objetos y el próximo mes de abril de 2021 se hará una exposición a través de las redes con todos los objetos aportados.

Estas y otras iniciativas en las redes sociales nos permitieron ver la brecha digital existente en gran parte de nuestro público adulto que realmente es el $80 \%$ de nuestro público habitual y ello nos llevó a organizar un curso de aprendizaje. Con el nombre "Conéctate al mundo" durante el verano de 2020 ofrecimos pequeños cursos a personas mayores de 60 años para facilitarles herramientas digitales para estar en contacto con la actividad del Museo y para poder acceder a un sinfín de contenidos culturales. Estos cursos fueron impartidos por nuestras becarias, la comunicación y conocimientos intergeneracionales fueron muy positivos.

\section{Base de datos accesibles de los yacimientos arqueológicos}

Como hemos explicado anteriormente el Museo de Historia de Manacor gestiona 3 yacimientos arqueológicos, s'Hospitalet Vell, Son Peretó y sa Ferradura. En 2019 desarrollamos el cambio de los paneles de los yacimientos de s'Hospitalet Vell y Son Peretó con la intención de hacerlos más accesibles a todos los públicos y para eso necesitamos usar la tecnología y la digitalización de los contenidos para que la información que había sobre el soporte físico que se encuentra en el yacimiento pudiese ser entendida por cualquier visitante.

De esta manera se crearon paneles que cumplían con los parámetros de accesibilidad universal (contraste de texto y fondo, tamaño de la fuente, textos validados en LF, dibujos e imágenes explicativos para apoyar los textos), además creamos códigos QR que dirigen a los visitantes a la base de datos accesible donde encuentran toda la información que hay sobre el soporte físico en formato digital y descargable para poder verla, escucharla y compartirla a través de su dispositivo móvil. 
La base de datos accesible ${ }^{7}$ está creada por la misma empresa que la página web, Mopis Web, y además de poder llegar a ella mediante los paneles físicos que están situados en los yacimientos, se accede también a través del apartado investigación de la página web.

La versatilidad de esta base de datos es que también se gestiona por el personal del museo, se pueden ir incluyendo enlaces de interés, fotografías. Además de estar conectada con la colección virtual del museo en Sketchfab y el canal de YouTube del museo.

\section{Recursos humanos y presupuestarios}

Como ya ha quedado latente en la comunicación, el museo cuenta con unos recursos humanos y presupuestarios limitados. Creemos que es importante desglosar cuántos de ellos se han dedicado al desarrollo de la estrategia digital del museo para poder planificar en los presupuestos futuros los medios humanos y económicos necesarios para afianzar y conseguir la madurez digital ${ }^{8}$.

Hemos desglosado los gastos en tres bloques que atiende a los tres apartados recogidos en el desarrollo de la innovación: página web, redes sociales y base de datos accesible.

Las tareas desarrolladas por el personal contratado por el museo están cuantificadas en horas de trabajo, ya que cada administración fija los honorarios de sus trabajadores. Pensamos que de esta forma es cálculo es más objetivo para las personas que puedan leer este artículo.

\footnotetext{
${ }^{7}$ https://accessible.museudemanacor.com/api/ca/place/3

${ }^{8}$ Capacidad de un individuo o una organización para usar, administrar, crear y comprender lo digital de una manera contextual, holística y con propósito (Informe Culture 24,

https://pro.europeana.eu/files/Europeana_Professional/Publications/Digital\%20transformation\%20reports/The\%20digital\%20transf ormation $\% 20$ agenda $\% 20$ and $\% 20$ GLAMs $\% 20-\% 20$ Culture24\%20findings $\% 20$ and $\% 20$ outcomes.pdf, p. 7 )
} 
Museos pequeños, estrategias digitales a medida. El caso del Museu d'Història de Manacor, (Mallorca).

Tabla 1. Recursos invertidos en la renovación de la página web

\begin{tabular}{|c|c|c|c|}
\hline \multirow[t]{2}{*}{ Pagina web } & Año 2018 & Año 2019 & Año 2020 \\
\hline & Gastos & Gastos & Gastos \\
\hline $\begin{array}{lr}\text { Diseño } & \text { de la } \\
\text { página } & \text { web, } \\
\text { alquiler } & \text { de } \\
\text { hosting y } & \text { dominio }\end{array}$ & $2.145,44 €$ & & \\
\hline $\begin{array}{l}\text { Mantenimiento } \\
\text { de la web }\end{array}$ & & $319 €$ & $604,20 €$ \\
\hline $\begin{array}{l}\text { Colección virtual } \\
\text { (Sketchfab) }\end{array}$ & & $2.100 €$ & \\
\hline $\begin{array}{l}\text { Traducción } \\
\text { páginas, } \\
\text { castellano e inglés }\end{array}$ & $235,31 €$ & $366 €$ & $305,32 €$ \\
\hline Total $^{9}$ & $2380,75 €$ & $2785 €$ & $909,52 €$ \\
\hline \multirow{2}{*}{$\begin{array}{l}\text { Trabajo interno } \\
\text { museo: }\end{array}$} & Año 2018 & Año 2019 & Año 2020 \\
\hline & Horas & Horas & Horas \\
\hline Documentación & 100 & 20 & 10 \\
\hline $\begin{array}{ll}\text { Grabación } & \text { de } \\
\text { notas de voz } & \end{array}$ & 10 & - & 10 \\
\hline Reuniones & 10 & 2 & 2 \\
\hline Formación & 10 & 3 & 3 \\
\hline Total & 130 & 25 & 25 \\
\hline
\end{tabular}

Diseño tabla: María José Rivas

\footnotetext{
9 En las cifras económicas el IVA está incluido.
} 
Tabla 2. Recursos invertidos en redes sociales

\begin{tabular}{|l|l|l|l|l|}
\hline $\begin{array}{l}\text { Redes } \\
\text { sociales }^{10}\end{array}$ & $\begin{array}{l}\text { Año 2017 } \\
\text { Horas }^{11}\end{array}$ & $\begin{array}{l}\text { Año 2018 } \\
\text { Horas }\end{array}$ & $\begin{array}{l}\text { Año 2019 } \\
\text { Horas }\end{array}$ & $\begin{array}{l}\text { Año 2020 } \\
\text { Horas }\end{array}$ \\
\hline $\begin{array}{l}\text { Instagram }^{\mathbf{1 2}} \\
\text { Facebook } \\
\text { Twitter }\end{array}$ & 60 & 60 & 120 & 180 \\
\hline YouTube $^{\mathbf{1 3}}$ & - & - & 18 & 2 \\
\hline Formación $^{\mathbf{1 4}}$ & 10 & 10 & 36 & 20 \\
\hline Total & $\mathbf{7 0}$ & $\mathbf{7 0}$ & $\mathbf{1 7 4}$ & $\mathbf{2 0 2}$ \\
\hline
\end{tabular}

Diseño tabla: María José Rivas

Tabla 3. Recursos invertidos en base de datos accesible

\begin{tabular}{|l|l|l|}
\hline $\begin{array}{l}\text { Base de datos } \\
\text { accesible }\end{array}$ & Año 2019 & Año 2020 \\
\hline $\begin{array}{l}\text { Trabajo técnico } \\
\text { Mopis Web }\end{array}$ & $1774,44 €$ & \\
\hline Grabación videos & $1.500,01 €$ & $266 €$ \\
\hline Subtítulos videos & $209 €$ & \\
\hline $\begin{array}{l}\text { Encargo redacción } \\
\text { paneles Son Peretó }\end{array}$ & $1.200,32 €$ & $157,30 €$ \\
\hline $\begin{array}{l}\text { Traducción del } \\
\text { contenido }\end{array}$ & $479,47 €$ & \\
\hline Validación LF & $214,17 €$ & \\
\hline
\end{tabular}

\footnotetext{
${ }^{10}$ Este apartado es gestionado directamente por el personal del Museo, en esta tabla hemos reflejado las horas anuales destinadas a cada una de las redes sociales

${ }^{11}$ Este cálculo es el resultado de dedicarle a las 3 redes sociales una media de 45 minutos diarios (de lunes a viernes).

${ }^{12}$ Instagram comenzó a usarse en 2017, Twitter en 2019 y Facebook en 2020.

${ }^{13}$ El cálculo las horas dedicadas a YouTube es una media de 10 minutos por cada vídeo subido a la plataforma.

${ }^{14}$ Este apartado hace referencia a las horas dedicadas a la formación autodidacta para el uso de las redes sociales (visionar tutoriales, lectura de foros, pruebas de ensayo error, instalación de aplicaciones,). En 2020 se realizó un curso de formación del uso de redes sociales ofrecido por el Consell de Mallorca, destacamos que la importancia de la formación ofrecida por profesionales para poder hacer un buen uso de las redes.
} 
Museos pequeños, estrategias digitales a medida. El caso del Museu d'Història de Manacor, (Mallorca).

\begin{tabular}{|l|l|l|}
\hline $\begin{array}{l}\text { Mantenimiento } \\
\text { técnico de la base } \\
\text { de datos }\end{array}$ & $245 €$ \\
\hline Total & $\mathbf{5 . 3 9 0} €$ & \\
\hline $\begin{array}{l}\text { Trabajo interno } \\
\text { museo }\end{array}$ & Año 2019 & $\mathbf{6 6 8 , 3} €$ \\
\cline { 2 - 4 } & Horas 2020 \\
\hline $\begin{array}{l}\text { Documentación } \\
\text { fe }\end{array}$ & 30 & Horas \\
\hline $\begin{array}{l}\text { Formación } \\
\text { notas de voz para } \\
\text { los vídeos }\end{array}$ & 10 & 3 \\
\hline Total & $\mathbf{4 3}$ & $\mathbf{3}$ \\
\hline
\end{tabular}

Diseño tabla: María José Rivas

Tabla 4. Gastos totales

\begin{tabular}{|l|l|l|l|l|}
\hline Gastos & $\mathbf{2 0 1 8}$ & $\mathbf{2 0 1 9}$ & $\mathbf{2 0 2 0}$ & \\
\hline Total & 2380,75 & 8175 & 1577,72 & $\mathbf{9 8 5 2 , 7 2}$ \\
\hline
\end{tabular}

Diseño tabla: María José Rivas

Tabla 5. Horas totales invertidas

\begin{tabular}{|l|l|l|l|l|l|}
\hline Horas & $\mathbf{2 0 1 7}$ & $\mathbf{2 0 1 8}$ & $\mathbf{2 0 1 9}$ & $\mathbf{2 0 2 0}$ & \\
\hline Total & 70 & 200 & 242 & 230 & $\mathbf{7 4 2}$ \\
\hline
\end{tabular}

Diseño tabla: María José Rivas

\footnotetext{
${ }^{15}$ Estos gastos fueron sufragados por la subvención para la adecuación de yacimientos arqueológicos otorgada por el Consell de Mallorca.
} 


\section{Resultados}

Este apartado tiene dos vertientes: una cuantificable, hecha con el recuento de usuarios que utilizan la página web, la base de datos accesible, la colección virtual o seguidores en redes sociales y, por otra, las acciones que hemos podido llevar gracias al desarrollo de nuestro entorno digital.

En cuanto al recuento de usuarios podemos decir que empleamos las herramientas gratuitas que nos ofrecen las plataformas y que hemos aprendido a usarlas de forma autodidacta. No cabe decir, que este es un tema en el cual nos falta formación para poder hacer mejor uso de los datos, pero que los indicadores que ya manejamos nos ayudan a tener una idea de la incidencia del entorno digital del museo en todas las plataformas o herramientas que hemos implementado.

Gracias a Google Analytics tenemos una respuesta inmediata sobre el público virtual que visita la página web. De esta manera sabemos que desde la renovación de la página web en mayo de 2018 hasta febrero de 2021 la han visitado 15.566 usuarios, que el apartado más visitado es el de educación y que nuestra página se consulta principalmente en catalán y en castellano, entre otros aspectos.

También hacemos uso de las estadísticas del canal de YouTube abierto en 2018 para saber que hasta febrero de 2021 cuenta con 2.014 visualizaciones. Y que uno de los vídeos más visto es un taller en línea con 112 visualizaciones.

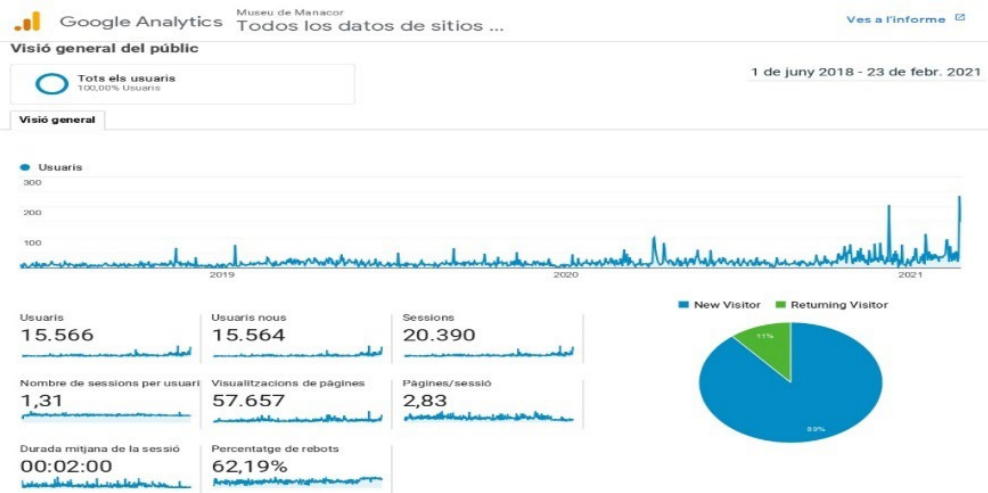

Fig. 2. Estadísticas de los visitantes de la página web (febrero 2019) 
Museos pequeños, estrategias digitales a medida. El caso del Museu d'Història de Manacor, (Mallorca).

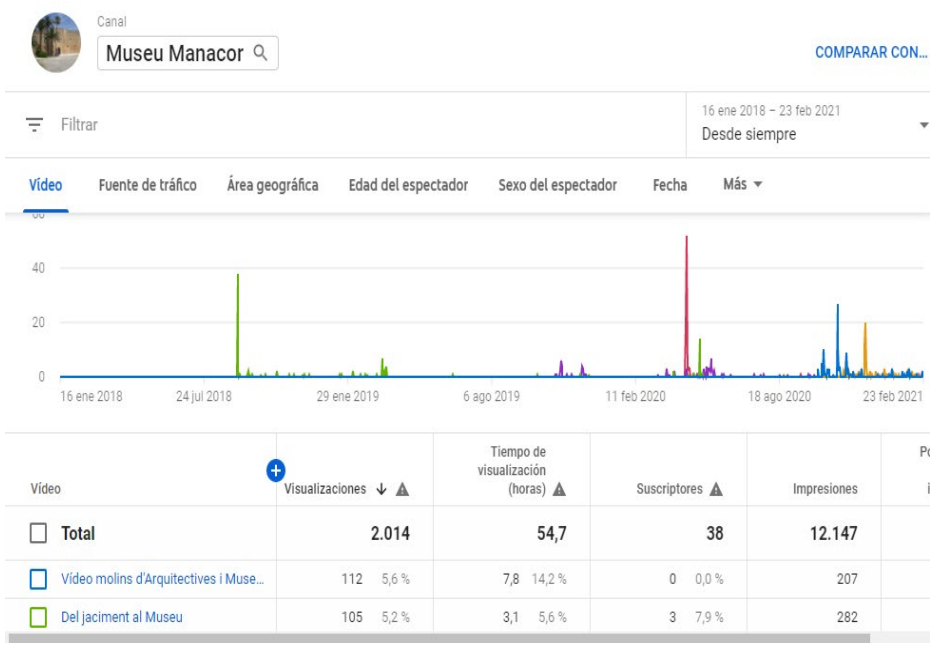

Fig. 3. Estadísticas canal YouTube (febrero 2019)

El recuento de seguidores de las redes sociales lo hemos agrupado en esta tabla, en la cual se ve también el incrementento de seguidores que se ha dado durante el último año.

Tabla 6. Seguidores de las redes sociales mayo 2020-febrero 2021

\begin{tabular}{|l|l|l|l|l|}
\hline \multirow{2}{*}{$\begin{array}{l}\text { Seguidores } \\
\text { redes sociales }\end{array}$} & Instagram & Facebook & Twitter & YouTube \\
\cline { 2 - 5 } & $\mathrm{N}^{\mathrm{o}}$ seguidores & $\mathrm{N}^{\mathrm{o}}$ seguidores & $\mathrm{N}^{\mathrm{o}}$ seguidores & \\
\hline Mayo 2020 & 1634 & 174 & 311 & 29 \\
\hline Febrero 2021 & 2007 & 544 & 525 & 38 \\
\hline
\end{tabular}

Diseño: María José Rivas 
La colección virtual del Museo que está en la plataforma Sketchfab y a la cual también se puede acceder mediante la página web cuenta con 88 seguidores y más de 17.000 visitas.

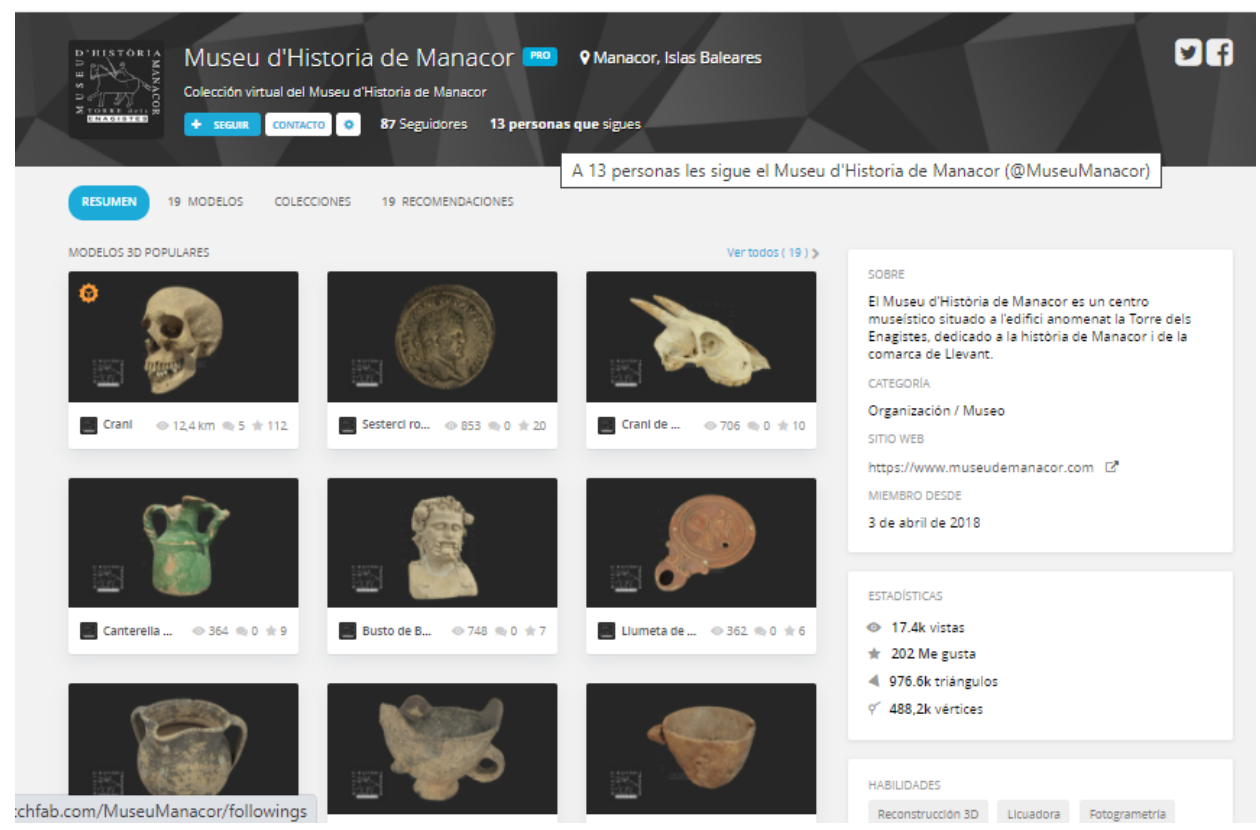

Fig. 4. Página colección virtual Museo de Historia de Manacor en Sketchfab (febrero 2019)

Creemos que hacer una suma acumulativa de todos los usuarios que visitan alguna de las plataformas anteriores o nos siguen en redes sociales sería un dato erróneo porque suponemos que son muchas las personas que a la vez visitan la página y nos siguen en redes. Nos queda una asignatura pendiente para los próximos años, hacer un estudio de público digital en todas las plataformas que mantenemos activas para poder entender y conocer a nuestros visitantes digitales.

Muchas de las acciones llevadas a cabo durante parte de 2020 y 2021, (periodo en el cual el museo ha estado cerrado o abierto con algunas restricciones), se han podido llevar a cabo por tener acceso a herramientas y plataformas digitales. Además de las ya mencionadas anteriormente, queremos resaltar las siguientes iniciativas:

En la página web se han implementados 3 apartados nuevos: juegos en línea, talleres en línea y cuadernos didácticos, para tener recursos disponibles accesibles para público familiar.

Celebración del Día del Libro y del Día Internacional de los Museos 2020 de manera virtual con una programación que quería atender los intereses de todas las personas, pero sobre todo pensando en contenidos divertidos para los más pequeños. 
Museos pequeños, estrategias digitales a medida. El caso del Museu d'Història de Manacor, (Mallorca).

Hemos mantenido el contacto directo con los socios y socias de la Asociación de Amigos del museo y con todas las personas voluntarias mediante grupos de WhatsApp.

Hemos participado junto con los creadores del blog «Tant és ara com abans» en una serie de vídeos enfocados en los trabajos del campo para darlos a conocer al público joven.

Desde el inicio del curso se ofrece la posibilidad de hacer videoconferencias y talleres en línea en las escuelas que lo soliciten.

\section{Conclusiones}

La creación del entorno digital del museo no ha sido el resultado de una planificación estratégica al uso. Primero se comenzaron a crear herramientas digitales con el propósito de aprovecharlas en la difusión de los contenidos y actividades del museo; mediante el uso que hicimos de ellas nos dimos cuenta de que estábamos ante un mundo que crecía y evolucionaba muy rápido y que no encajaba con el sistema rígido de la administración. Este hecho, dio como resultado que la estructura laboral del museo empezara de cero en un campo desconocido sin ningún tipo de apoyo que no fuese el departamento de informática del propio ayuntamiento que generalmente solo se dedica a la gestión de los equipos informáticos y la red del museo. Encontrarnos con esa realidad nos hace plantearnos que la formación para la transformación digital de las instituciones museísticas debe estar actualizada y ser competencia también de las administraciones. Así sacaremos el máximo provecho de las nuevas herramientas y medios de comunicación que se nos presentan a través de la digitalización.

También nos hemos dado cuenta de que crear herramientas/plataformas digitales es un trabajo que involucra al equipo del museo, como se puede ver en las tablas de recursos del apartado desarrollo de la tecnología. Para que el resultado sea óptimo se han se crear equipos conjuntos entre las empresas que crean y diseñan las herramientas y la plantilla de trabajadores del museo, no creemos que sea un servicio que se pueda externalizar $100 \%$.

Somos conscientes que nuestra transformación digital está empezando y hemos querido apostar porque el mundo digital y físico se complemente y se ayuden, sin duda el primero se ha nutrido del segundo. Hemos aprovechado recursos y documentación existentes para crear la página web, pero en la medida que la creábamos abríamos nuestra mente a nuevas posibilidades que se podían extender en el mundo físico. Comentamos los siguientes ejemplos:

Los códigos QR que hay en la entrada de cada sala nos llevan a las notas de voz que está colgadas en la página web para poder realizar la visita sin tener que leer los paneles, es decir, funcionan como una audioguía.

Del mismo modo, la colección virtual del museo se puede disfrutar en 3D a través de la web, pero a la vez las réplicas de estos objetos se pueden tocar en las salas del museo. 
La estrategia que hemos elegido es la de nutrir ambos mundos para que nos ayuden a facilitar que cualquier visitante tenga una experiencia grata cuando entre por algunas de nuestras puertas, ya sean físicas o digitales.

Efectivamente navegar por la web del museo y visitarlo son dos acciones diferentes, pero ambas deben ser satisfactorias para los visitantes. Nada sustituirá el encuentro físico en el museo con las piezas, con el edificio, con el personal del museo, con la comunidad. Pero si tenemos un recurso tan potente y universal como la tecnología debemos aprovecharla para que cualquier persona pueda acercarse al museo a través de ella y para eso hay que destinar recursos económicos y humanos porque si la usamos adecuadamente nos hará crecer como institución. En este sentido, nuestra experiencia nos demuestra que la gente no va al Museo sólo para aprender sino para socializarse y entrar en contacto con gente que tiene sus mismas inquietudes. Por este motivo, el reto de futuro es crear contenidos digitales que cumplan también esta función, no sólo de receptor de información individual sino de experiencias compartidas en grupo.

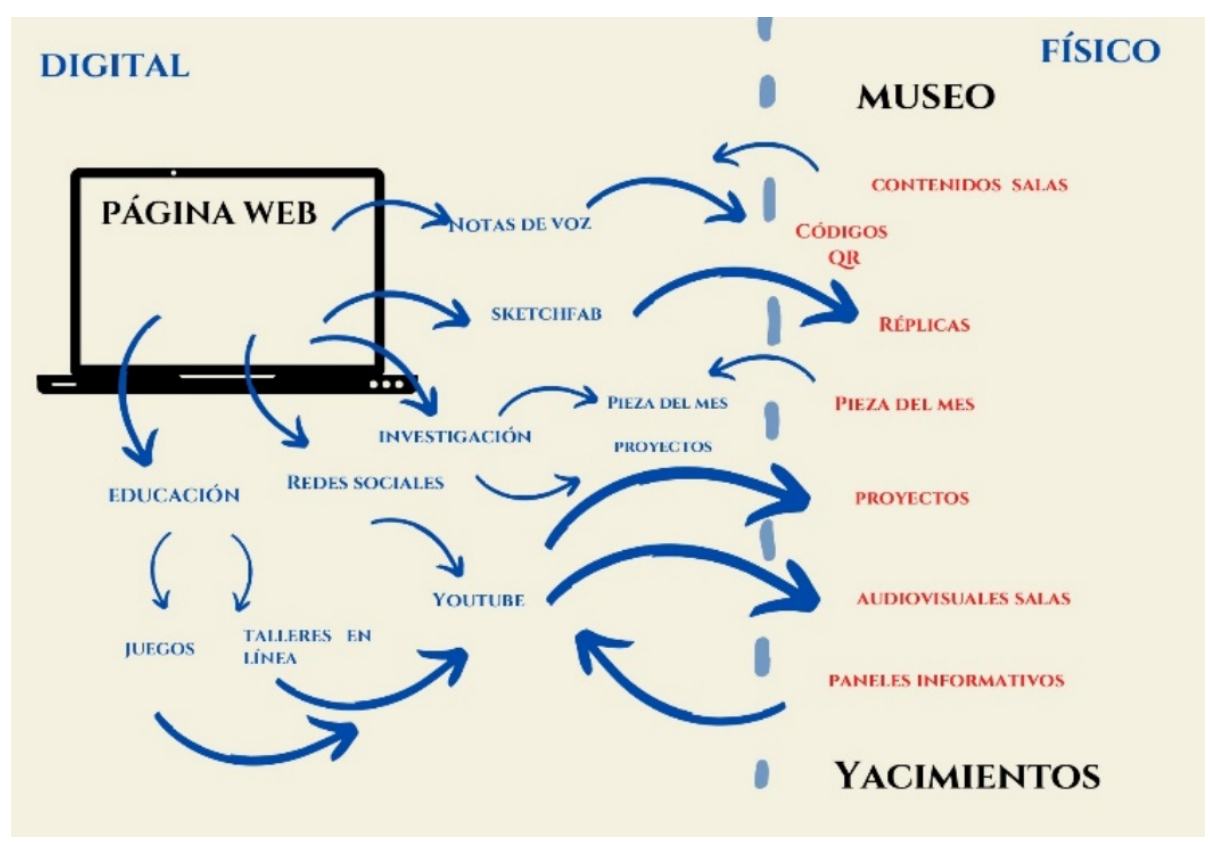

Diseño: María José Rivas

Fig. 5. Esquema de las relaciones entre el mundo físico y digital del Museo de Historia de Manacor

Trabajar con herramientas digitales nos ha hecho reflexionar sobre:

- La brecha digital que existe dentro y fuera del museo. 
Museos pequeños, estrategias digitales a medida. El caso del Museu d'Història de Manacor, (Mallorca).

- El trabajo en red nos permite compartir conocimientos y amplificar nuestro radio de difusión.

- No existen fórmulas digitales estándar, cada institución debe ir creando su entorno digital a medida, donde se sienta cómodo, que le permita dar lo mejor de sí y que esté dentro de su presupuesto.

- Confiamos en la digitalización como una puerta abierta para divulgar los conocimientos del museo sin límite de tiempo y espacio, usando todas las maneras posibles que nos ofrece la tecnología.

- Necesitamos formación continua cualificada.

- La tecnología es fundamental para dar accesibilidad al museo.

- El Museo quiere ser parte del buen uso de las nuevas tecnologías y fomentarlo dentro de su comunidad.

Durante la crisis sanitaria que estamos viviendo el mundo digital nos ha permitido, a muchos, comunicarnos, establecer relaciones, aprender, divertirnos e incluso vernos, aunque fuese detrás de una pantalla. La web y las redes sociales del museo han sido nuestro medio para seguir conectados con las personas y acompañarlos con contenidos variados, juegos, conexiones en directos, talleres, etc. También ha sido importante para nosotros sentir la respuesta de cada entrada colgada en las redes o en la web porque igualmente hemos sentido que había personas detrás recibiendo y valorando nuestro trabajo. En los tiempos que hemos vivido ha sido elemental contar con estas herramientas que nos han permitido acompañarnos mutuamente e interactuar. 


\section{Referencias}

AULA FORMATIVA (2015). Ejemplos de páginas web de museos y galerías de arte. https://blog.aulaformativa.com/ejemplos-de-paginas-web-de-museos-y-galerias-de-arte/ [Consulta: 1 de marzo de 2017].

CULTURE 24 (2020). The Digital Transformation Agenda and GLAMs. https://pro.europeana.eu/files/Europeana_Professional/Publications/Digital\%20transfor mation\%20reports/The\%20digital\%20transformation\%20agenda\%20and\%20GLAMs\% 20-\%20Culture24\%20findings\%20and\%20outcomes.pdf [Consulta:25 de enero de 2021].

ESPINOSA RUIZ, A. y BONMATÍ LLEDÓ, C., (ed) (2013). Manual de accesibilidad e inclusión en museos y lugares de patrimonio cultural y natural. Gijón: Trea.

EVE MUSEOS E INNOVACIÓN (2018). Creación web del museo: guía básica. https://evemuseografia.com/2018/01/18/creacion-web-del-museo-guia-basica/ [Consulta: 1 de febrero de 2018].

RIVAS ANTEQUERA, Mª J. y SALAS BURGUERA, Mª M. (2019). "Un museo para todos. El proyecto de accesibilidad del Museu d'Història de Manacor”. Boletín del Museo Arqueológico Nacional, Madrid, p. 289-296.

RIVAS ANTEQUERA, Mª J. y SALAS BURGUERA, Ma M., (2020). "Nous reptes. Projecte d'accessibilitat del Museu d'Història de Manacor. VIII Jornades d'Arqueologia de les Illes Balears, Palma, p.51-59.

RUIZ, B.; PAJARES, J.; MORENO, L.; GÁLVEZ Ma C.; SOLANO J., (2008). Guías multimedia accesibles. El museo para todos. Madrid: Real Patronato sobre Discapacidad. Disponible en: http://sid.usal.es/idocs/F8/FDO21399/museo_para_todos.pdf. [Consulta: 19 de diciembre de 2020]. 